\title{
EXPERIENCIAS INTERNACIONALES EN EL USO PRODUCTIVO DE LAS REMESAS
}

\author{
ERIKA MONTOYA ZAVALA*
}

\begin{abstract}
RESUMEN. Este trabajo recoge algunas evidencias empíricas acerca de la inversión de las remesas en actividades productivas encabezadas por migrantes de retorno o por familiares de migrantes en América Latina, Asia y África. El objetivo es detectar los factores que posibilitan la inversión productiva de las remesas e identificar los aportes teóricos y conceptuales de diversos autores que han abordado ese problema. Se concluye que existen factores que han limitado la inversión productiva de las remesa, como la pobreza extrema de los migrantes y sus familias, y que existen otros factores que por el contrario la estimulan, como las habilidades y destrezas que el migrante desarrolla en el país receptor y las distintas contribuciones de las organizaciones de migrantes, particularmente las que se derivan de su interés por mejorar las condiciones de vida de los habitantes de sus comunidades de origen. Palabras Claves. Negocios remeseros, subsidio-remesas, remesas domésticas, remesas forzadas.
\end{abstract}

ABSTRACT. This work compiles some empirical evidence on the investment of remittances in productive endeavors headed by returned migrants or by migrants' relatives in Latin America, Asia, and Africa. The objective is to detect the factors that make possible the productive investment of remittances, and to identify the theoretical and conceptual contributions made by several of the authors that have studied this problem. The conclusion is that there exist factors that have limited the productive investment of remittances, such as migrants and their relatives' extreme poverty, and there exist other factors that by the contrary stimulate productive investment, such as the skills and abilities that migrants develop in the receiving country and different contributions made by migrant organizations, particularly, the ones seeking to improve the living conditions of the people in the communities of origin.

KeYWORDS. Remittance business, remittance subsidy, domestic remittances, torced remittances.

" Profesora investigadora de la Escuela de Estudios Internacionales y Políticas Públicas de la Universidad Autónoma de Sinaloa. Estudiante del octavo semestre del Doctorado en Ciencias Sociales en la Universidad de Guadalajara. Correo electrónico: ‘erikikamontoya00@hotmail.com». 


\section{INTRODUCCIÓN}

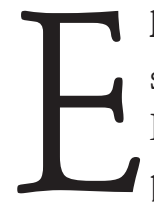

1 tema de la migración internacional, las remesas y su impacto en los países expulsores de migrantes tiene una historia y literatura muy extensas. En distintas partes del mundo, el fenómeno de las remesas y su inversión productiva ha despertado el interés de políticos, académicos y estudiantes, quienes han desarrollado análisis empíricos y teóricos sobre este fenómeno. La mayoría de los estudios han tratado de cuantificar las remesas, de analizar la canalización y utilización de las mismas (Garson, 1993; Nayyar, 1994; Sofranko e Idris, 1999; Leinbach y Watkins, 1998; Andrade-Eekhoff, 1999; Benavides et. al., 2004) o intentan analizar los mecanismos que promueven la inversión de los ahorros de los migrantes en el exterior (Stanton, 1992; Portes y Guarnizo, 1991; Ortiz, 1997). Es importante conocer y analizar los resultados obtenidos en estos estudios, que están ubicados en contextos económicos, sociales, políticos e históricos específicos, pues arrojan resultados que nos permiten analizar los factores que incentivan el uso productivo de las remesas.

Este ensayo tiene como objetivo mostrar un panorama internacional del uso productivo de las remesas, exponiendo, con base a los estudios empíricos realizados en otras latitudes, que las remesas, ubicadas en un contexto económico, político y social determinado, pueden funcionar como fuente de financiamiento para negocios de migrantes de retorno, o para los familiares de los migrantes en su país de origen. Queremos resumir algunos ejemplos de estudios que se han desarrollado en otros países sobre las remesas y su inversión en actividades productivas, abarcando algunos casos de los países de América Latina, Asia y África, subrayando los aportes teóricos y conceptuales que han desarrollado diversos autores, con la finalidad de conocer los factores que incentivan la inversión productiva de las remesas

\section{REMESAS Y LA FORMACIÓN DE PEQUEÑAS EMPRESAS EN}

\section{EL SALVADOR Y REPÚBLICA DOMINICANA}

La importancia de las remesas, en los países de América Latina, es tanto cuantitativa como cualitativa. El envío de remesas de los emigrantes latinoamericanos y caribeños, a sus países, superó los 45,000 millones de dólares en 2004. Cantidad que convierte, a la región latinoamericana, en el principal destino mundial de remesas y que excede, de nuevo, la suma de toda la inversión extranjera directa y la cooperación externa recibida en la región. Según estimaciones del Banco Interamericano de Desarrollo en 2005, las remesas en la región alcanzaron los 55,000 millones de dólares. México fue el principal receptor de remesas en América Latina en 2004 (con más de 16,000 millones de dólares), seguido por Brasil $(5,624)$ y Colombia $(3,857)$. Para países como El Salvador, Nicaragua, Jamaica y otros, las remesas re- 
presentan $10 \%$ o más del PIB y son una de las fuentes más importantes de divisas. En el plano de los hogares, las remesas son una fuente crucial de ingresos para familias que viven en la pobreza (BID, 2004). Para ilustrar un poco lo que pasa con el uso de las remesas en actividades productivas, así como la instalación de negocios remeseros, ${ }^{1}$ se va a analizar el caso de El Salvador y República Dominicana.

\section{LA INVERSIÓN PRODUCTIVA DE LAS REMESAS, LA EXPERIENCIA DE LOS SALVADOREÑOS}

Al hablar de las remesas en El Salvador, es necesario hacer un alto para entender los aspectos históricos y económicos más importantes que han caracterizado la migración en esta región, con el fin de tener una visión más amplia del contexto donde se encaja este fenómeno de las remesas familiares y su inversión productiva.

La migración de los salvadoreños a Estados Unidos está caracterizada por ser multicausal; las primeras evidencias de migración se remontan a la década de los sesentas, cuando algunas personas se fueron a los Estados Unidos por motivos económicos. Un segundo punto importante, de la historia de la migración salvadoreña, se presenta en la década de los ochentas, período en el que los salvadoreños se vieron impulsados a migrar principalmente por la guerra civil, por problemas económicos y la falta de alternativas laborales. Un tercer momento importante fue la década de los noventas, cuando el fenómeno de la migración tomó más fuerza, siendo la razón principal, para salir del país, las dificultades económicas y laborales. Esta última oleada de migrantes ha sido estimulada, también, por las facilidades logísticas y el apoyo económico derivados de la integración e institucionalización de redes familiares, por lo que algunos salvadoreños emigraron para reunirse con sus familiares radicados en EU (Benavides et. al., 2004).

En Estados Unidos, los salvadoreños se han concentrado en enclaves principales y secundarios. El principal enclave es Los Ángeles, con enclaves secundarios en Anaheim y Riverside, todos en la parte sur de California. Otros enclaves primarios son San Francisco, California; Houston, Texas; Washington D.C. y Nueva York, todos con agrupaciones secundarias en la periferia de las ciudades. El perfil de la migración salvadoreña se caracteriza por ser, principalmente, de las áreas urbanas, entre los 12 y 45 años de edad y, en su mayoría, hombres. Además de estas características, se ha encontrado que los migrantes poseen, en promedio, un nivel académico superior a los no-migrantes, es decir que El Salvador sufre de lo que se describe como el «brain drain» o fuga de cerebros (Andrade-Eekhoff, 1999).

\footnotetext{
${ }^{1}$ Son los negocios que se establecieron con la aportación de las remesas, que se han ampliado con éstas, que han comprado maquinaria, tierras, ganado con ellas y los negocios que compran sus insumos con este tipo de envíos monetarios.
} 
El monto de las remesas que llegan a El Salvador, por sí solo, es de considerable importancia en la economía del país. El ingreso de remesas al país centroamericano, durante 2004, alcanzó una cifra récord de 2,547.6 millones de dólares, equivalentes al 16.2 por ciento del producto interno bruto. Las remesas durante 2003 totalizaron 2,105.3 millones de dólares, por lo que, en 2004, el crecimiento fue del 21 por ciento. Y unos 340,964 hogares salvadoreños, de un total de $1,589,941$, reciben remesas de familiares en el exterior. ${ }^{2}$

Estudios empíricos realizados en El Salvador, sobre el uso de las remesas, demuestran la importancia de éstas como fuente de financiamiento en pequeños negocios de algunas localidades salvadoreñas (Benavides et.al, 2004; Andrade-Eekhoff, 1999; Funkhouser, 1992, 1995; Lopez y Seligoson, 1991).

Con base en los estudios realizados por Baires en 1997 y por Lungo, Andrade-Eekhoff, y S. Baires en 1996 (citado en Andrade-Eekhoff, 1999), donde se exploraron las relaciones entre el proceso de migración, las remesas y el desarrollo de la pequeña empresa en El Salvador, podemos identificar tres aspectos potenciales que permiten construir una red de migrantes empresarios en su lugar de origen. Hecho que hay que rescatar de la experiencia de los salvadoreños en el uso productivo de las remesas.

El primero de ellos es que existe una migración de retorno, no masiva, pero que trae consigo recursos económicos y sociales que le permite iniciar negocios en su lugar de origen. En los estudios señalados anteriormente, se encontró que los migrantes de retorno invierten sus ahorros en su localidad de origen, aprovechando la adquisición de capital humano del migrante en el exterior. Los ejemplos de negocios remeseros incluyen a un joven que aprendió la carpintería en un curso de la secundaria y, al regresar a El Salvador, utilizó sus conocimientos para poner su negocio, así como a varios empresarios que aprendieron nuevas habilidades en mecánica automotriz. Además, los conceptos empresariales como «servicio al cliente», sanidad, organización del negocio y relaciones patrón-empleado, son algunos ejemplos de actitudes mencionadas, por los empresarios, como importantes para tener éxito y una ventaja competitiva en El Salvador, resultado del aprendizaje como migrantes.

El segundo aspecto importante que se detectó, en los negocios que tienen una relación con el fenómeno migratorio, es el aprendizaje del uso de nuevas tecnologías, principalmente equipo de trabajo, para luego importar este equipo al abrir su negocio en El Salvador. Esta tecnología no es «tecnología de punta», sino tecnología relativamente fácil de utilizar y conseguir, tales como computadoras para el diagnóstico de vehículos; bombas y compresores; equipo para lavar carros;

${ }^{2}$ Banco Interamericano de Desarrollo (BID), http://www.iadb.org/news/, consultado en diciembre de 2004. 
maquinaría industrial para lavar trastes; maquinaria para panadería y de otros tipos. Una gran parte de esta maquinaria o equipo (que no es nuevo sino usado) ha sido adaptada para las condiciones específicas de los negocios en El Salvador. El entrenamiento especializado, que los dueños de negocios han recibido en el exterior, junto con la incorporación de tecnologías son algunos de los elementos que ayudan a asegurar el éxito de las empresas analizadas.

Por último, otro aspecto importante de la experiencia salvadoreña, en el uso productivo de las remesas, es que los empresarios salvadoreños, que tienen una relación con la migración, se han beneficiado de la red de contactos que mantienen en Estados Unidos, tanto para abastecer su negocio como para adquirir equipo de trabajo, o para mantenerse al corriente sobre cambios en el mercado, tecnología y precios. Las redes de contactos desarrolladas en el exterior ejercen un impacto positivo en la empresa, ya que permiten el acceso a productos, información, compradores y vendedores, entre otras cosas.

Por otro lado, Lopez y Seligoson (1991) realizaron un estudio sobre el impacto de las remesas en pequeños negocios de 9 municipios de San Salvador, ${ }^{3}$ que fueron clasificados en cinco tipos: tiendas, zapateros, vendedores ambulantes, restaurantes y otros (211 negocios en total). Los resultados de este estudio arrojan que, en cada tipo de negocios, las remesas representan alrededor de la mitad del total de los ingresos y son un recurso fundamental en los ingresos de los hogares. En cada una de las empresas (por lo general pequeñas), de 44 a $48 \%$ de las remesas recibidas son invertidas directamente en los negocios. Los autores argumentan que esta inversión pudiera fungir como un subsidio para dichos establecimientos $y$, en algunos casos, juega el rol de sustituir los créditos bancarios.

En este mismo estudio, los resultados muestran que de un cuarto a un tercio (de 26 a 38\%) de los negocios, en San Salvador, fueron establecidos como resultado de la disponibilidad de remesas. Y de un tercio a dos tercios de los entrevistados (de un 38 a un 69\%) reportan que el futuro de su negocio depende del flujo constante de ingresos por remesas. Por otra parte, las principales razones para no invertir las remesas en los negocios son la irregularidad y los montos pequeños recibidos, esto de acuerdo a las respuestas de aproximadamente la mitad de todos los entrevistados. Un porcentaje muy pequeño respondió no saber en qué invertir las remesas (de cuatro a 16 por ciento en los distintos grupos de negocios), o no invertir por no necesitar hacerlo o por el clima desfavorable para ello.

Otro estudio fue el realizado por Blanca Mirna Benavides, Xenia Ortiz, Claudia Marina Silva y Lilian Vega (2004) en La Labor. Este cantón es un área rural perteneciente al municipio de San Sebastián, departamento de San Vicente, El Sal-

\footnotetext{
${ }^{3}$ Los nueve municipios son: San Salvador, Nueva San Salvador, Ayutuxtepeque, Mejicanos, Cuscatan-
} cingo, Illipango, San Marcos, Panchimalco y El grupo Auytuxtepeque-Mejicanos-Cuscatancingo. 
vador. Uno de los objetivos principales de este trabajo fue conocer si las remesas, que reciben los hogares del citado cantón, permiten tener ingresos adicionales que contribuyan a satisfacer las necesidades básicas de las familias con migrantes, posibilitando, de esta manera, salir del círculo de la pobreza en que se desenvuelven. Los autores esperaban encontrar, como resultado, que los hogares con migrantes, al recibir remesas, tuvieran mayores propensiones a ahorrar e invertir $y$, además, pudieran generar una mejor calidad de consumo, que los hogares sin migrantes.

Para cumplir con este objetivo analizaron, primeramente, la situación social y económica de los pobladores de esta localidad, encontrando que, para el año 2002, la población aproximada del cantón era de 349 familias, las cuales obtenían, mayoritariamente, sus ingresos de la agricultura; otros ingresos provenían de la producción artesanal (telares) y de las microempresas de subsistencia. En la actualidad, ninguna de las actividades económicas son lo suficientemente representativas como para poder cubrir los gastos totales del hogar, por lo que muchas familias viven en pobreza y extrema pobreza, mientras que especialmente la juventud se aventura a migrar hacia E.U.

Los resultados de la investigación muestran que, los hogares con migrantes del cantón de La Labor, están teniendo recursos adicionales que les permiten consumir más bienes y servicios en relación con los hogares sin migrantes, pero que sus ingresos no son lo suficientemente altos como para permitirles prácticas generalizadas de ahorro formal, endeudamiento e inversión productiva. La existencia de migrantes es un factor importante para que un hogar salga de la pobreza extrema, pues el porcentaje de éstos, en pobreza relativa, es significativamente mayor en los hogares que reciben remesas, mientras que casi la totalidad de las familias sin migrantes son pobres extremos.

Es en este contexto, en el que la pobreza constituye una característica que forma parte de la vida cotidiana de la mayoría de las personas, que las redes familiares y/o sociales se tornan en mecanismo fundamental para la supervivencia de los hogares y de la comunidad misma. Estos lazos de identificación con la familia y con el territorio explican, además, fenómenos como que, cada año, las personas migrantes lleguen a visitar a sus familiares, o la aparición de las remesas colectivas, que datan de principios de los años noventas. En este contexto, el Comité de Migrantes de Los Ángeles, fundado en 1995, y la Asociación de Desarrollo Comunitario (ADESCO), de principios de los noventa, están jugando un importante papel en la nivelación de algunos aspectos fundamentales del desarrollo humano, como son la infraestructura, la educación y la salud, contribuyendo, así, a mejorar las condiciones de vida de los pobladores de La Labor.

En cuestión de enseñanza, es un rubro que está cubierto para todos los hogares, gracias, en gran medida, a las inversiones de las remesas colectivas. La Labor muestra que los hogares con migrantes, gracias a las remesas familiares, están mejorando su calidad de vida; mientras que la comunidad en general, gracias a las remesas colectivas, está logrando mayor equidad en ciertos aspectos del 
desarrollo humano, como son la salud y la educación. Las remesas, sin embargo, ayudan pero no son suficientes para sacar a los hogares de la pobreza, pues las causas que la originan son estructurales. En este sentido, se puede concluir que la economía en los hogares de La Labor (ya tengan o no migrantes) no va más allá de la subsistencia, sin existir prácticas generalizadas de ahorro, crédito e inversión.

\section{SUBSIDIO-REMESAS EN LOS MICRO-NEGOCIOS \\ DE LA REPÚBLICA DOMINICANA}

Unos 2 millones de dominicanos adultos viven fuera de su patria y, la mayoría de éstos, residen en Estados Unidos, con una gran concentración en el área metropolitana de Nueva York, donde habitan unos 700,000 de ellos. Más del 70 por ciento de esos trabajadores envían dinero, de manera periódica, a sus familiares, típicamente entre 135, 150 ó 165 dólares por vez. Durante el 2003, las remesas llegaron a los 2,217 millones de dólares y, para el 2004, más de 2,400 millones de dólares fueron captados por concepto de remesas en República Dominicana (FOMIN-BID, 2004).

Un alto porcentaje de la población dominicana se ve beneficiada con las remesas (el 38 por ciento), proporción que los coloca como la más alta de Latinoamérica y muy por delante de El Salvador que, con un 28 por ciento, se sitúa en segundo lugar. Los que envían más dinero son las personas de entre 36 y 49 años, en su mayoría mujeres, de un nivel socioeconómico bajo y medio-bajo. El 92 por ciento de las personas que envían dinero a República Dominicana viven, en EU, de manera legal, ya sea como nacionalizados o como residentes. ${ }^{4}$

En un estudio realizado por Ortiz (1997) en 60 áreas de República Dominicana, abarcando Santo Domingo, zonas urbanas y rurales -en las cuales se realizó un censo, registrando todos los hogares y negocios, identificando 1,176 micro y pequeñas empresas-, se encontró que el 81 por ciento de los dueños de negocios tiene algún miembro de su familia residiendo en el extranjero. Uno de cada cinco hogares de dueños de empresas reciben dinero enviado desde el exterior, es decir, el 21.8 por ciento.

En este trabajo podemos destacar cuatro aspectos importantes que caracterizan los negocios remeseros de República Dominicana. Primero, se encontró que mientras más estrechas son las relaciones de parentesco, entre el dueño del negocio y el migrante, es mayor la probabilidad de recepción de remesas. Éstas llegan, en mayor proporción, a los hogares de propietarios con familiares directos (hijos, padres, hermanos, abuelos) residentes en el extranjero y, cuando las relaciones de

\footnotetext{
${ }^{4}$ «Remesas a República Dominicana aumentarán 27 por ciento este año», «http://www.terra.com/actualidad/articulo/html/act187157.htms.
} 
familiares tienden a ser más distantes, como es el caso de familiares colaterales (primos, tíos, sobrinos), es mayor la proporción de quienes no reciben remesas.

Segundo, los hogares de mujeres propietarias de negocios reciben más remesas que los hogares de hombres propietarios. Con base en el estudio realizado, se encontró que el 46.8 por ciento de los negocios son propiedad de mujeres y, el 26 por ciento de los hogares de mujeres propietarias de micro y pequeñas empresas, reciben remesas provenientes de sus familiares y amigos en el extranjero. Esta proporción se reduce (18.7 por ciento) cuando las unidades son de propiedad masculina. La mujer dominicana que ha migrado envía dinero, a sus familiares, en mayor proporción que el hombre, pues más de la mitad de las remesas (51.1 por ciento) que llegan a los hogares de los dueños de micro y pequeños negocios son remitidas por mujeres. Tercero, los hogares de los propietarios que tienen menor nivel económico reciben más remesas, ya que los negocios que tienen menos empleados y los que tienen menos ventas son los que reciben mayor cantidad de envíos monetarios.

Y cuarto, las remesas que llegan a los negocios, en República Dominicana, constituyen una fuente de ingreso que aumenta el presupuesto de los hogares de los dueños de negocios; tales fondos se utilizan, principalmente, para gastos familiares (un 84.9 por ciento), como alimentación, educación, vivienda y gastos de salud. Solo el 7 por ciento de las remesas recibidas son destinadas, por los dueños, a inversiones en el negocio (materia prima, mercancía, equipos y maquinarias). Un $8.1 \%$ de las remesas es usado para pagar deudas contraídas por el remitente o como ahorro. La mayoría de las mujeres empresarias (92.8\%) utilizan las remesas para cubrir gastos relativos al sostenimiento de su familia, un porcentaje mayor al de hombres propietarios (71.3\%). Por el contrario, el 15.6\% de los dueños destinan las remesas a inversiones en el negocio y sólo el 1.5\% de las propietarias realizan gastos de su empresa con el dinero que reciben del extranjero. Las remesas representan, para muchos dueños de negocios, el punto de equilibrio necesario para mantener funcionando la empresa $y$, a la vez, satisfacer, aunque sea de forma mínima, sus necesidades básicas de alimentación y vivienda.

De igual manera, el estudio realizado por Portes y Guarnizo (1991), donde se analiza la migración de los dominicanos a Nueva York y sus efectos en el desarrollo regional, encuentra que los dominicanos han invertido sus remesas en negocios que no son remunerativos, por ello necesitan que algún miembro de la familia continúe migrando para inyectarle, continuamente, remesas al negocio, con el fin de que siga subsistiendo; por consiguiente, las relaciones entre el migrante y sus familiares, en su lugar de origen, son un aspecto importante que ayuda a desarrollar un sector de pequeños negocios ligados con la migración pero, también, las relaciones y los contactos que logran establecer en el extranjero le permiten, al migrante, establecer una base como seguro y soporte de su negocio dominicano. Es decir, si el negocio establecido en República Dominicana no cumple con las expectativas económicas del migrante, los propietarios recurren a trabajar en EU por temporadas del año para conseguir recursos, sin los cuales el establecimiento 
no podría funcionar. Los negocios establecidos con ayuda de remesas son, básicamente, negocios de subsistencia, donde se emplea a familiares sin otorgarles un sueldo fijo, además, estos negocios no son rentables, se tiene que volver a migrar para mantenerlos o contar con un miembro de la familia trabajando en otro país para que envíe remesas y poder abastecer de insumos o mercado al negocio familiar. Es por esto que los autores arguyen que las remesas se han convertido en una especie de subsidio para la formación de negocios en República Dominicana. Por lo tanto, tenemos otro tipo de motivación para migrar, ya no es la sobrevivencia, sino el objetivo de incrementar los ingresos familiares.

\section{LAS REMESAS Y SU IMPACTO}

EN LOS PAÍ́SES DE ASIA

Asia, la región más heterogénea y más poblada, es también el área más diversa en términos de migraciones internacionales. Entre otras, incluye las migraciones de trabajadores a los países productores de petróleo en Asia Occidental; la red migratoria creada alrededor de los nuevos países industrializados del Pacífico (Taiwán, Hong Kong, Singapur, como países importadores de mano de obra); el flujo de migraciones étnicas permanentes a Israel; movimientos de refugiados (principalmente de Afganistán, Camboya, Laos y Vietnam) así como varios flujos inter-regionales (Roig, 2002).

CUADRO 1

Remesas de migrantes en el mundo, distribución porcentual por región receptora

\begin{tabular}{|c|c|c|c|c|c|c|c|c|}
\hline REGIÓN & 1995 & 1996 & 1997 & 1998 & 1999 & 2000 & 2001 & 2002 \\
\hline Total mundial & 100.0 & 100.0 & 100.0 & 100.0 & 100.0 & 100.0 & 100.0 & 100.0 \\
\hline Latinoamérica & 23.2 & 21.0 & 19.9 & 22.6 & 25.1 & 28.1 & 30.9 & 32.3 \\
\hline África & 8.5 & 8.4 & 8.7 & 9.2 & 8.9 & 9.7 & 11.6 & 10.4 \\
\hline Asia & 23.3 & 27.9 & 33.8 & 25.1 & 27.3 & 23.9 & 22.8 & 26.3 \\
\hline Europa & 10.0 & 10.0 & 9.7 & 13.8 & 11.6 & 11.7 & 8.9 & 7.7 \\
\hline Oriente Medio & 11.1 & 10.6 & 10.6 & 10.3 & 9.8 & 9.4 & 8.9 & 8.1 \\
\hline Países Industrializados & 24.0 & 22.1 & 17.4 & 19.0 & 17.3 & 17.2 & 17.0 & 15.1 \\
\hline
\end{tabular}

Fuente: Munzele Mainbo, Samuel, et al (2005), "Migrant Labor Remittances in the South Asia Region", Banco Mundial, Reporte 31577, (Febrero).

La asiática es la segunda región que capta el monto más alto de remesas, en el año 2002 recibieron el 26.3 por ciento de las remesas mundiales (ver cuadro 
uno). Dentro de Asia, entre los países que más remesas recibieron en el año 2000, encontramos a India en primer lugar, seguida por Filipinas, China, Bangladesh y Palestina. Sin embargo, unos cuantos países concentran la mayoría de las remesas, por ejemplo, India contabiliza el $62.5 \%$ de los flujos de remesas en el sur de Asia, mientras que Filipinas recibe el $58 \%$ del este del citado continente y el Pacífico (Nyberg, 2004a). En este apartado retomamos los ejemplos de India y Pakistán para ilustrar lo que sucede, en el sur de Asia, con el uso de las remesas en actividades productivas.

ASPECTOS IMPORTANTES DE LA EXPERIENCIA

EN EL USO PRODUCTIVO DE LAS REMESAS DE INDIA

La diáspora de India, con 20 millones de migrantes esparcidos por todos los continentes y en la mayoría de los países del mundo, es un gran potencial para el desarrollo de las localidades de este país. Nayyar (1994) provee un análisis de las tendencias del flujo migratorio de India a los países industrializados de Estados Unidos, Canadá y el Reino Unido, entre el periodo de 1951 a 1990, donde encontró que los Estados Unidos recibieron el número más grande de migrantes hindúes. Sin embargo, esta migración representa una proporción muy pequeña del total de los migrantes, tanto en EU como en Canadá. Del total de los migrantes en dichos países, los migrantes hindúes constituyeron alrededor del 3.6 y 6 por ciento, respectivamente, en la década de los ochenta. La proporción de hindúes inmigrantes en el Reino Unido declinó, drásticamente, de 20\%, en la década de los sesenta, a 10\% durante la década de los ochenta. En comparación, el promedio anual de migrantes hindúes a EU se incrementó de 26,184 personas, durante la década de los ochenta (3.6\% del total de migrantes), a 38,330 (4.5\% del total de migrantes) en la década de los noventa. En el caso de Canadá, el promedio anual de migrantes hindúes se incrementó de 7,930, durante la década de los ochenta ( $6 \%$ de la migración total), a 13,770 durante la década de los noventa (7\% del total de los migrantes). Otro aspecto importante del flujo migratorio de India a los países industrializados, durante la década de los noventa, fue el flujo migratorio hacia nuevos países, este periodo también fue testigo del flujo de migrantes hindúes profesionales, especialmente en alta tecnología, hacia países como Australia, Alemania, Japón y Malasia.

Las remesas recibidas por las familias radicadas en India han contribuido, a nivel macroeconómico, a mantener la balanza de pagos, mejorar la salud y educación de los habitantes de localidades y pueblos en dicho país, así como a optimizar la infraestructura de sus hogares y, en tiempos de crisis o desastres naturales, los migrantes organizados han contribuido para el alivio y rehabilitación de las victimas. El flujo de remesas, durante las tres décadas pasadas, ha financiado gran proporción del déficit de la balanza de pagos y reducido su déficit. Durante la década de los ochenta, cuando India enfrentó una crisis en su balanza de pagos, 
las remesas estuvieron en posición de financiar el 40 por ciento de su déficit comercial (Srivastava, 2003).

Asimismo, las remesas tienen un impacto considerable en las economías regionales de India. En Kerela, por ejemplo, estudios empíricos han demostrado que el desempleo ha disminuido alrededor de 3 por ciento, a consecuencia de la migración. También se ha reportado un incremento en los ingresos per cápita, como resultado de las remesas, y se ha incrementado el gasto en consumo. El gasto per cápita, en Kerela, excede el porcentaje nacional, además tiene una significante consecuencia sobre la disminución de los niveles de pobreza (Srivastava, 2003; Greame, 2003).

Estudios realizados, en algunas regiones de India, muestran un panorama más específico de los factores que incentivan o limitan la inversión productiva de las remesas en esa región. En un estudio realizado por Ballard (2003), donde se exploró el impacto de las remesas en el distrito de Jalandhar, en India, y en el Distrito de Mirpur, en la línea fronteriza entre Pakistán y parte de Cachemira - ambas áreas con un gran número de migrantes establecidos en el Reino Unido-, se encontraron resultados contradictorios. En el caso de Jalandhar se muestra que, durante la década de los setenta, esta localidad fue beneficiada por la revolución verde, envolviéndola en el uso de las nuevas tecnologías en las semillas, la aplicación de los fertilizantes, la irrigación intensiva y el uso masivo de maquinaria agrícola para manejar cultivos de rendimientos más pesados. Sin embargo, también muestra que el uso exitoso de estas nuevas tecnologías y técnicas de cultivo requirieron de un importante nivel de inversión de capital y, las familias que tuvieron a un familiar establecido en el Reino Unido, lograron la posibilidad de tomar ventaja de las nuevas oportunidades. Muchos migrantes estuvieron dispuestos a enviar dinero para la compra de tractores y la adquisición de maquinaria para poder con los altos rendimientos agrícolas. Es decir, las remesas de los migrantes no fueron la causa de la revolución verde en Jalandhar, pero si contribuyeron en este proceso de transformación agrícola.

Por otra parte, Ballard (2003), en Mirpur, encontró resultados opuestos. A pesar de ser un área con un potencial agrícola considerable y un flujo de remesas más sostenido, estos fondos sólo estimularon un «boom» en la construcción de casas y del sector servicios en general. En contraste a lo que se presentó en Jalandhar, la localidad de Mirpur no mostró señales de crecimiento en la productividad; debido a que este último factor se encontraba concentrado en las remesas manejadas por el sector servicios, la localidad mostraba una clara dependencia hacia tales envíos monetarios. Muchas casas fueron abandonadas por sus dueños migrantes, mientras que la agricultura continúo un camino de pérdidas y la opción de los jóvenes fue migrar. El autor concluye, con base en estos dos casos, que el uso de las remesas en actividades productivas no es resultado de diferencias en actitudes empresariales, sino consecuencia de diferentes ambientes e infraestructura, así como de características económicas y políticas de estos dos distritos. 
Uno de los estudios empíricos realizados en Pakistán es el de Adams (citado por Munzele et al., 2005a), en donde se examinó la manera en que se usan y gastan las remesas. Adams analizó 500 casas rurales en Pakistán, aunque esto no es representativo de todas las áreas rurales de dicho país; sin embargo, sus resultados son sugerentes. Encontró que las remesas llegan a los hogares más ricos; en tales hogares, las remesas representan el 13.8 por ciento de los ingresos, mientras que, en los hogares más pobres, las remesas representaron sólo el 1.0 por ciento del total de los ingresos. El autor argumenta que la causa de este fenómeno son los costos altos de la migración. En el Pakistán rural, la mayoría de los migrantes internacionales se van a trabajar al Golfo Pérsico, y el costo promedio de la migración es muy alto para la clase más pobre.

Además, encontró que, a pesar del alto costo de la tierra en Pakistán, las remesas permiten la acumulación de capital y, en lugar de aumentar el consumo de comida, ropa o ceremonias sociales, los migrantes pakistaníes rurales están ahorrando e invirtiendo en la compra de tierras más que sus contrapartes no migrantes. Sin embargo, el pakistaní rural no está invirtiendo en la instalación de negocios, aparentemente, en este rubro es más bajo el nivel de inversión que en la compra de tierras, debido a que la mayoría de los migrante rurales son empleados de gobierno y agricultores, los cuales carecen de habilidades mercantiles para establecer un negocio cuando regresan a su país de origen. El migrante tiende a invertir en áreas que conoce y domina, como la agricultura (Adams, 1998, citado por Munzele et al., 2005a).

Por otra parte, en un estudio realizado por Sofranco e Idris (1999), a 170 familias de una pequeña localidad de Pakistán, se encontró que pocas son las remesas que se invierten en negocios, encontrándose 54 familias con negocios remeseros (es decir, que invirtieron las remesas en la instalación de un negocio o en algo relativo al funcionamiento de un negocio): 14 familias iniciaron un negocio con remesas, 19 mejoraron un negocio ya establecido, 7 expandieron el negocio a otro miembro de la familia, 19 construyeron o expandieron el local del negocio, y 15 compraron un vehículo con propósitos comerciales o de uso en el negocio. Se encontró que el factor que más estuvo presente, en el establecimiento de negocios, fue la anterioridad de la experiencia en el establecimiento de esta actividad dentro de la familia.

\section{REMESAS INTERNACIONALES Y DOMÉSTICAS}

EN LOS PAÍSES AFRICANOS

Las migraciones de África tienen varios componentes: existe un flujo de migración internacional e interna entre países; el flujo de la migración internacional va, 
principalmente, hacia Europa Occidental y a los países productores de petróleo del Oeste Asiático, en especial procedente del Norte de África y, a pesar de que los estudios existentes indican que los destinos de los migrantes norteafricanos se han diversificado, la mayoría sigue migrando a Francia. En cuanto a los flujos de migración interna, los principales países receptores de trabajadores son Costa de Marfil y África del Sur, cuya prosperidad económica, especialmente en el sector minero, ha atraído un flujo significativo de migrantes africanos y de otras regiones (Roig, 2002).

La importancia de la migración internacional de África se ve reflejada en los montos de remesas que recibe cada año. Este continente recibió 12 billones de dólares en 2002. La mayor cantidad de remesas recibidas en África se concentran en el Norte (74\% del total de remesas), debido al fuerte y constante flujo de migración que va a laborar a Europa. El Este de África es la región que ocupa el segundo lugar en la captación de remesas (13\%), seguido del Sur y el Oeste de África (7\% y $5 \%$ respectivamente). El centro de África recibe menos del 1\% de las remesas en este continente (Sander y Munzele, 2003: 7-8).

Contabilizando el flujo de remesas por país, Egipto es el que más recibe, seguido de Marruecos, Nigeria, Túnez y Sudán; sin embargo, en comparación a los flujos financieros totales por país, en Marruecos, las remesas representan el 66\%, en Egipto, 51\%, al igual que en Túnez Sander y Munzele, 2003: 35).

Existen aspectos particulares que caracterizan la migración y las remesas en África, que resulta importante conocer para que nos faciliten el análisis y la comprensión de los aspectos que influyen para incentivar o reprimir el uso de las remesas en actividades productivas. El flujo de remesas que llega a África se caracteriza por tres aspectos importantes: primero, las remesas llegan por medios informales, es decir, los migrantes envían parte de su salario en efectivo a sus familiares, en sus comunidades de origen, a través de amigos, parientes y/o conocidos. El uso de canales informales es debido a que en algunas regiones no existe un sistema financiero que permita el flujo formal de remesas; a pesar de que han aumentado las oficinas de compañías financieras, como Western Union, en ciertas áreas las transferencias de bolsillo siguen siendo la principal forma de enviar dinero. En Sudán, por ejemplo, las remesas informales representan el 80\% del total de envíos captados. Incluso, en algunos mercados locales y regionales, existen camiones que prestan el servicio de transportación de estas remesas o transferencia de dinero. Esto trae, como consecuencia, que no se contabilice una parte de estos flujos y que el total de remesas recibidas sea subestimado, al mismo tiempo se dificulta la canalización del uso de remesas en actividades productivas (Sander y Munzele, 2003).

Una segunda característica, de este flujo de remesas en África, es que también llegan desde regiones dentro de dicho continente, las llamadas remesas domésticas. Existen flujos de remesas de regiones urbanas a rurales y de rurales a rurales, que muchas veces no son contabilizados y, en algunos casos, llegan a ser 
tan importantes como las remesas internacionales. Entre los países africanos que envían este tipo de remesas encontramos a Sudáfrica, Angola, Egipto y Bostswana (Sander y Munzele, 2003: 6-8).

Un tercer aspecto es que los flujos de remesas se han presentado inconstantes a través de los años. Las remesas en África han crecido lentamente y, en ocasiones, han decaído, su punto máximo fue alcanzado en 1992, contabilizando 10.7 billones de dólares y, en 2000, bajaron a 7.8 billones de dólares, debido, en parte, a que la región presenta una pobre y rudimentaria base de datos, pero, también, a los cambios que se presentan regionalmente, como la liberalización del sistema financiero en Uganda, el incremento de refugiados en el Este de África y la expansión de operadoras de transferencias de dinero en esta misma región (Sander y Munzele, 2003). Sin embargo, estas características generales se rompen al analizar país por país y, más aún, si se estudia una localidad en particular, es por ello que presentamos algunos resultados obtenidos en investigaciones hechas en lugares específicos de África, como son Marruecos, Túnez y Comores.

\section{INVERSIÓN PRODUCTIVA DE}

LOS MARROQUÍES MIGRANTES EN EUROPA

En 1990 Marruecos recibió remesas por valor de 16,573 millones de dirhams, cifra que se elevó hasta 19,001 millones de dirhams casi diez años después, en 1999. Repentinamente, en 2001, casi se duplicaron hasta 36,162.8 millones de dirhams, manteniéndose en ese nivel en 2002 y 2003. Estas remesas provienen, principalmente, de los migrantes establecidos en Francia, con 44.5\% del total de envíos captados, seguidas por Italia y España, con $12.7 \%$ y 9.2\% respectivamente (Sandell, 2005). Podemos dimensionar la importancia de las remesas recibidas en Marruecos, si las comparamos con el déficit de la balanza de pagos de este país. La captación de remesas, en el 2000, representó el 53\% del déficit en la balanza de cuenta corriente, aumentando a 83\% en el 2001 y 81.3\% en el 2002 (Nyberg, 2004b).

Por otra parte, estudios empíricos orientados en un nivel micro han demostrado que en las áreas que cuentan con una tradición migratoria, como la región del Rif, se ha visto un dinamismo muy importante en el sector servicios y el 71\% de los hogares con migrantes han comprado tierras, construido casas o ampliado sus viviendas. Varios trabajos profesionales y ocupaciones se han visto beneficiados por la migración y las remesas: yeseros, herreros, tiendas de muebles, plomeros, electricistas y tiendas de electrodomésticos. Otro tipo de inversión se ha efectuado en la compra de taxis, vans, cafeterías, tiendas de té, restaurantes y hoteles. En Targuist, siete de veinte hoteles son propiedad de migrantes. Patrones similares se presentan en Tetouan y Tánger, donde agencias de viajes y casas de cambio ha sido instaladas (Nyberg, 2004b).

De la misma manera, Garson (1993) realizó un estudio para analizar el rol 
que juegan las remesas en el desarrollo regional del norte de África, abarcando la migración de los pobladores de los países de Marruecos, Argelia y Túnez hacia Francia. En dicho estudio encontró que las remesas enviadas dependen del tiempo de la migración: si la ola de la migración es relativamente reciente, como es el caso de los marroquíes y tunecinos en Francia, el ahorro salarial es un componente importante de las remesas $y$, cuando las olas migratorias ya tienen tiempo, el componente significativo de las remesas son las pensiones. Además, arguye que los determinantes para el envió de remesas tienen que ver con las variables de la trayectoria del trabajo del migrante, la historia familiar, la situación económica en el país receptor y las oportunidades que emergen en el país de origen.

De acuerdo con los resultados de la investigación, los marroquíes son los que presentan una mayor propensión al ahorro. Garson argumenta que la falta de oportunidades o acceso a un proyecto mayor, en su localidad de origen, puede incentivar la inversión de los ahorros del migrante en el país destino y, en contraste, cualquier medida de liberalización económica o política, o cualquier mejora en el sistema económico y financiero del país de origen, estimula el incremento de las remesas.

En los tres países, Argelia, Marruecos y Túnez, se han implementado programas para motivar el envió de remesas a su localidad de origen y su uso en actividades productivas (algunos ejemplos son: exención de impuestos para todos los bienes importados por los migrantes de retorno definitivo a su lugar de origen, cuentas de ahorros en moneda extranjera en su país de origen, creación de fondos de ahorros de migrantes para financiar actividades sociales y educativas). Sin embargo, el autor concluye que, mientras que las medidas gubernamentales no orienten sus intereses a los de los migrantes y sus familias, ningún programa encaminado a aumentar el envió de remesas y su uso en actividades productivas va a funcionar.

No obstante, la evidencia es contradictoria, Collinson (1996) argumenta que, en Marruecos, los migrantes de retorno que tienen ciertas habilidades no encajan con las necesidades del mercado laboral local y que el impacto de las remesas es ambiguo, que se destinan, en mayor medida, al consumo en vez de invertirlas productivamente. En el mismo sentido están los hallazgos de Gallina (2004), en un estudio realizado a 30 hogares de dos provincias de Marruecos: Taroudant y Beni Mellal, así como a 50 familias marroquíes en Dinamarca, donde se obtuvo, como resultado, que las remesas sí han jugado un importante papel en la economía y la infraestructura local de ciertas áreas, pero los migrantes prefieren invertir en centros urbanos más grandes, como Casablanca y Agadir, donde las oportunidades del mercado son mayores o porque ello les da un estatus social más alto. Lo anterior afecta el impacto de las remesas en el desarrollo local de las áreas rurales marginadas y aumenta la brecha del desarrollo entre las zonas rurales y urbanas. En ambas provincias estudiadas, la falta de infraestructura, como electricidad, agua potable y carreteras, limita el uso productivo de las remesas. Otro aspecto, detectado en este estudio, que limita la inversión productiva de las remesas, es la falta de educación de los migrantes y la lentitud de los trámites del 
sistema burocrático, así como las prácticas de corrupción que se presentan en las localidades estudiadas.

LAS REMESAS FORZADAS EN TÚNEZ

Debido a su proximidad geográfica, los flujos de migración y remesas circulan entre Túnez e Italia así como los países exportadores de petróleo del Este de Asia. Las remesas en Túnez representaron el $4.7 \%$ de su Producto Interno Brito y el $14.9 \%$ de las exportaciones realizadas en 2002.

Sin embargo, la migración y las remesas también fluyen dentro de África, característica que comparten la mayoría de los países africanos y que, asimismo, es importante contabilizar y analizar. En este sentido, Dostie y Vencatachellum (2004) realizaron un estudio sobre las remesas que envían las jóvenes trabajadores domesticas a sus familias (jóvenes que migran de áreas rurales a Túnez), encontrando que existe un importante flujo de remesas forzadas de jóvenes trabajadoras domésticas, es decir, el sueldo de las jóvenes es depositado directamente a los padres de familia. El estudio, realizado a 500 jóvenes trabajadoras domésticas, mostró que el 75\% de las jóvenes se inician en este tipo de trabajo antes de cumplir los 16 años, al tiempo que reciben un ingreso menor a un tercio del salario mínimo; sin embargo, se encontró que también reciben otro tipo de pago no monetario, como un dormitorio, servicios de salud y, en ocasiones, los empleadores envían regalos a los padres.

Al 39\% de las trabajadoras domésticas se les paga su salario depositándoles, directamente, a sus padres o a sus hermanos mayores, si aquéllos están muertos; solamente el $15 \%$ recibe entre $50 \%$ y $100 \%$ de su salario, porque el resto se les deposita a sus progenitores. Las trabajadoras domesticas que tienen hermanas menores que ellas son más propensas a enviar remesas forzadas, para pagar la educación de sus pequeñas familiares. Y, las trabajadoras domésticas que tienen hermanos menores, son más propensas a enviar remesas voluntariamente, debido a que esperan que, cuando el padre muera, el hermano se haga cargo económicamente de ellas. Sin embargo, estas remesas no presentan un potencial para ser invertidas en actividades productivas, ya que son utilizadas, principalmente, en gastos de consumo cotidiano y para solventar los gastos de educación de algún miembro del hogar.

\section{REMESAS Y DESARROLLO EN COMORES}

En la región africana de Comores también están presentes el fenómeno migratorio y los negocios remeseros; se estima que entre el $20 \%$ y el $25 \%$ de la población de Comores vive fuera de sus lugares de origen. La mayoría de ellos se encuen- 
tran en Francia; se calcula que el 95\% de esta diáspora proviene de Nagazidja, la isla más grande que compone la Unión de Comores. La experiencia migrante de Comores ha llevado a la formación de tres generaciones de migrantes en Francia; la primera generación la conforman las personas que migraron después de la independencia, que son generalmente hombres, con una cultura enraizada en Comores, estas personas son ahora jubilados. La segunda generación consiste en aquellos que migraron a una edad joven quienes, por lo general, cursaron parte de sus estudios en Comores y otra parte en Francia, son los mediadores entre las dos culturas y las otras dos generaciones, conforman la principal fuente de trabajo y son los más activos en las organizaciones de migrantes. La tercera generación son aquellas personas de origen comorano, nacidos y educados en Francia. Los más viejos de esta generación tienen alrededor de 25 años y empiezan a moverse en la fuerza laboral. Estos migrantes remiten alrededor de 36 millones de dólares anuales a Comores (Cruz, 2004).

Estas remesas, al igual que en la mayoría de las localidades receptoras, se utilizan principalmente para financiar el consumo diario de las familias. Pero se han detectado inversiones en la compra de vehículos para usarlos como taxis y en la importación de bienes para comercializar en pequeña escala. Son los migrantes de la segunda y tercera generación quienes, con mayor frecuencia, invierten sus remesas en actividades productivas, ya que estas generaciones de jóvenes son los que demandan un mejor uso de sus fondos y ahorros. Asimismo, las organizaciones de migrantes están presentes en dicha región, los comoranos en Francia han formado más de 500 asociaciones, la mayoría de ellas son informales, pero cientos más están registradas en la ley francesa sobre las organizaciones no lucrativas. Asimismo, se han creado escuelas — publicas y privadas-, centros de salud, farmacias, caminos rurales, estalaciones de agua potable, líneas y generadores de electricidad, campos deportivos, centros de jóvenes, librerías, mezquitas, todos estos proyectos financiados por las asociaciones de migrantes (Cruz, 2004).

\section{CONCLUSIONES}

La evidencia empírica de las remesas, como fuente de financiamiento para la implementación de negocios, está inconclusa. Podemos decir que el uso de las remesas en actividades productivas, en las localidades expulsoras de migrantes, es multicausal, depende del tipo de migración, del contexto histórico, del capital social, de las redes sociales, de la estructura particular de cada localidad y del ciclo de vida de los hogares; sin embargo, es necesario continuar realizando estudios empíricos que aporten piezas nuevas a este rompecabezas de aportes teóricos, metodológicos y conceptuales, para el análisis de las remesas y su uso productivo.

Lo que podemos concluir, con base a los estudios realizados en distintos contextos económicos y sociales, es que existen factores que han limitado el uso 
de las remesas en actividades productivas, como es la pobreza extrema en la que están inmersos los migrantes y sus familias. Asimismo, se presentan factores que han permitido y estimulado la inversión productiva de las remesas en distintos contextos espaciales y temporales, como las habilidades y destrezas que el migrante desarrolla en el país receptor, las organizaciones de migrantes y su interés por mejorar las condiciones de vida de los habitantes de las comunidades de origen, las redes de contactos que mantienen los migrantes de retorno con personas del país destino, las cuales les proporcionan información, tecnología y financiamiento, así como la experiencia del migrante y su familia en el manejo de negocios.

BIBLIOGRAFÍA

ANDRADE-Eekhoff, Katharine (1999), «El Intercambio Transnacional de Conocimientos: posibilidades a través de la Migración Salvadoreña», Estudio preparado para el Círculo de Aprendizaje sobre Migración Proyecto «Conectándonos al Futuro de El Salvador», ‘http://www.conectando.org.sv/Estrategia/EstudioMigracion.htm\#nternacional».

Benavide, Blanca Mirna S., Xenia Ortiz, Claudia Marina Silva, Lilian Vega (2004), «żPueden las remesas comprar el futuro? Estudio realizado en el cantón San José La Labor, municipio de San Sebastián, El Salvador», en Ecuador Debate, núm.63, ‘http://www.dlh.lahora.com.ec/paginas/debate/paginas/ debate1283.htm).

Ballard, Roger (2003), "Remittances and Economic Development», House of Commons Select Committee on International Development, hhttp:// www.art.man.ac.uk/casas/pdfpapers/selectctte.pdf».

Collinson, S. (1996), "Shore to shore. The politics of migration in Euro-Maghred relation», The Royal Institute of International Affairs, London, Middle East Programme.

Cruz, Vincent Da, Wolfgang Fengler y Adam Schwartzman (2004), "Remittances to Comoros. Volume, trends, impact and implication», en African region working paper series, Banco Mundial, núm. 75, «www.wordbank.org/afr/ wps/wp75.pdf?.

Dostie, Benoit y Désiré Vencatachellum (2004), Compulsory and voluntary remittances: evidence from child domestic workers in Tunisia, Cahier de recherché, núm. IEA-04-04, Montréal, pp. 1-46.

FunkHouser, E. (1992), «Mass Emigration, Remittances, and Economic Adjustment: The Case of El Salvador in the Late 1980s», en George Borjas y R. Freeman (eds.), Immigration and the Work Force, Chicago, University of Chicago Press.

FunKHOURSER, Edgar (1995), «Remittances from international migration: A comparison of El Salvador an Nicaragua», en The Review of Economics and Statistics, Harvard University, vol. LXXviI, núm. 1, febrero, pp. 137-146. 
Fomin-BID (Fondo Multilateral de Inversiones, Banco Interamericano de Desarro1lo) (2004), «Enviando dinero a casa: receptores de remesas en República Dominicana y remisores en Estados Unidos», Fomin-BID, New York, Columbia University.

Gallina, Andrea (2004), "Migration, financial floor and development in the Euro-Mediterranean area», INTRAW (United Nation International Research and Training Institute for the Advancement of Women), Research Report núm. 5, «www.un-istraw.org`.

Garson, Jean-Pierre (1993), "Financial Flow Generated by emigration and their impact on regional development», en Migration and Development, OCDE, París, pp. 275-287.

Graeme, Hugo (2003), «Migration and Development: A perspective from Asia», International Organzation for Migration (IOM), http://www.iom.int/documents/publication/en/mrs_14_2003.pdf\#search='Migration\%20and\% 20Development:A\%20Perspective\%20from\%20Asia'?.

Leinbach, Thomas R. y John F. Watkins (1998), «Remittances and Circulation Behavior in the Livelihood Process: Transmigrant Families in South Sumatra, Indonesia», en Economic Geography, vol. 74, núm. 1, pp. 45-63.

Lopez, J.R. y M.A. Seligson (1991), "Small Business Development in El Salvador: The Impact of Remittances», Commission for the Study of International Migration and Cooperative Economic Development, Working Papers, núm. 44, pp. 1-37.

Munzele Mainbo, Samuel et al. (2005), "Migrant Labor Remittances in the South Asia Region», Banco Mundial, reporte 31577, febrero.

NAYYAR, Deepak (1994), "Macro-economic Impact», en Migration, Remittances and Capital Flows. The Indian Experience, Bombay, Oxford University Press.

Nyberg Sorensen, Ninna (2004a), "The development dimension of migrant remittances», en Migration Policy Research, oIm, Working Papers Series, núm. 1, http://www.iom.int/DOCUMENTS/PUBLICATION/En/mpr1.pdf». (2004b), «Migrant Remittances as a Development Tool: The Case of Morocco», en Migration Policy Research, oIm, Working Papers Series, núm. 2, http:// www.iom.int/DOCUMENTS/PUBLICATION/EN/remittances_morocco.pdf).

ORTIZ, Marina (1997), Microempresa, migración y remesas en la República Dominicana, 1996-1997, Santo Domingo, Fondomicro.

PORTES, Alejandro y Luis Guarnizo (1991), Capitalistas del trópico. La Inmigración en los Estados Unidos y el Desarrollo de la Pequeña Empresa en la República Dominicana, Santo Domingo, Facultad Latinoamericana de Ciencias Sociales (FlACSO), Programa República Dominicana, The Johns Hopkins University.

RoIg Vila, Marta (2002), «Un análisis de las tendencias de la migración mundial», en Las migraciones internacionales en América Latina y el Caribe, SELA, núm. 65, http://www.sela.org/public_html/aa2k2/esp/cap/n65/cap65-8-1.htm).

SANDell, Rickard (2005), «Las remesas de los emigrantes en España: una oportu- 
nidad para la acción exterior», Real Instituto Elcano de Estudios Internacionales y Estratégicos, España, ‘http://www.realinstitutoelcano.org/documentos/167.asp.

Sander, Cersten y Samuel Munzele Mainbo (2005), "Migrant labor remittances in Africa: Reducing Obstacles to Developmental Contributions», Banco Mundial, African region working paper series, núm. 64, «www.wordbank. org/afr/wps/wp64.pdf).

SRIVASTAVA, Ravi (2003), "An overview of migration in India, its impacts and key issues», en Migration Development Pro-Poor Policy Choices in Asia, http:// www.livelihoods.org/hot_topics/docs/Dhaka_cp_2.pdf).

Sofranko, A.J. y Hkan Idris (1999), "Use of Overseas Migrant's Remittances to the Extended Family for Business Investment: A Research Note», en Rural Sociology, vol. 64, núm. 3, pp. 464-481.

Stanton Russel, Sharon (1992), «Migrant Remittances and Development», en International Migration, vol. xxx, pp. 267-287. 